\title{
Studies for Obtaining the Protocorms and Plantlets in Orchis pinetorum, Anacamptis pyramidalis, and Dactylorhiza nieschalkiorum under in vitro Conditions
}

\author{
Cevdet GÜMÜŞ' ${ }^{1}$, Şeküre Şebnem ELLİALTIOĞLU ${ }^{2}$, Şenel Birceyudum EMAN ${ }^{2}$ \\ ${ }^{1}$ Bartin University, Vocational School, Bartin, Turkey \\ ${ }^{2}$ Ankara University, Faculty of Agriculture, Deparment of Horticulture, Ankara, Turkey
}

\author{
*Corresponding Author: Ş. Şebnem ELLİALTIOĞLU, Department of Horticulture, Faculty of \\ Agriculture, Ankara University, Ankara, Turkey
}

\begin{abstract}
Orchis pinetorum, Anacamptis pyramidalis, and Dactylorhiza nieschalkiorum protocorms and plantlets were obtained via asymbiotic germination under in vitro conditions. For the germination of seeds, 4 basic nutrient media consisting of half-strength MS (1/2 MS), full-strength MS, Van Waes DeBergh (VW and $D B$ ), and Knudson $C$. The petri dishes contained orchid seeds and the nutrient medium semi-solidified with agar $(0.6 \%)$. cultures were incubated in darkness for the first 3 months and thereafter transferred to a light/dark photoperiod of 16/8 hours. At the end of the third month, protocorm rates were identified. They are subcultured every 4 weeks and $1 / 2$ MS medium was used as a transfer medium. The highest germination rate, protocorm rate and plant growth rate were obtained from Knudson C medium.
\end{abstract}

Keywords: Terrestrial orchids, in vitro, Germination, Protocorm, Medium.

\section{INTRODUCTION}

Orchis pinetorum, Anacamptis pyramidalis, and Dactylorhiza nieschalkiorum are the species belonging to the Orchidaceae family and are considered to be in the group of terrestrial orchids. They are hardy tuberous geophytes and tuber orchids. They blooms between the end of March and May in Turkey. The tubers, gathered from their habitats to produce 'Salep', generally spread along the coastline regions of Turkey.

Orchis pinetorum was first described from Cilicie (Anatolia) by Boissier and Kotschy in 1859 and is a member of the widespread $O$. mascula group of Orchis. Its name refers to the species frequent appearance in pine forest but although this is certainly a familiar habitat choice, its preferences generally are somewhat wider than this (Anonymous 2017, Davis 1984, Sezik 1984). The Latin name pyramidalis comes from the conical shape of the young inflorescence of Anacamptis pyramidalis (L) L.C.M. Richard. Once the flower is fully developed it becomes more cylindrical. It is known as Çam Salebi (Pine salep) in Turkey. Dactylorhiza nieschalkiorum H. Baumann \& Künkele is known Kocadudaklı and spread along the northwest regions of the Anatolia.

These orchids generally reproduce through the production of seeds in their natural habitat, although some orchid species are known to reproduce vegetative. The seeds of this species are very tiny and have a dust like structure. They have no endosperm and lose embryo viability quite quickly; thus, less than 5\% of them are able to germinate in their habitat. It takes an extremely a long time, 2-16 years, for the orchids to become mature after germination. The tubers produce just 1 fresh tuber each year and as ayoung tuber grows, it supersedes the older one and eventually, the older one vanishes (Sezik 1984, Gönülşen et al.1996).

To maintain their lifecycle, terrestrial orchids would not necessarily have a symbiotic relationship with fungi (Pierik 1987). Germination of orchid seeds in dark conditions is appropriate; however, some require both light and photoperiodic conditions and some others germinate at the same rate in both conditions (Arditti 1967). Hormone applications have no significant effect on the germination of orchid seeds (Arditti 1979).

The nutrient media composition plays an important role in orchid seed germination. Although epiphytic orchids needed intensive nutrient media, terrestrial orchids germinate better in a diluted 
media (Arditti 1979, Harvais 1973, Knudson 1946). Similarly, Pierik (1987) proposed that germination of orchid seeds was possible on a simple medium containing minerals and sugars. However, asymbiotic germination of orchid seeds seems to be influenced principally by the nitrogen source and nitrogen availability (Mead and Bulard 1975, 1979; Van Waes and DeBergh 1986; Van Waes 1987; Malmgren 1992, 1996; Kauth et al. 2006; Stewart and Kane 2006). This may be because of enzyme synthesis or activation within the developing protocorms. Thus, ensuring that organic nitrogen can be more readily utilized by young protocorms as available amino acids may bypass certain steps of the nitrogen assimilation process, such as the production of nitrate reductase, which requires several months following seed imbibition (Raghavan and Torrey 1964, Malmgren 1992, 1996).

Many terrestrial orchids are currently at great risk for extinction as a result of a multiplicity of threatening processes. We focus on orchid seed germination capabilities in vitro, specifically germination capability of a threatened species, Anacamptis palustris, compared to three other more common species (A. laxiflora, A. morio, and A. papilionacea), and also discuss its potential impact on orchid distribution and conservation. Asymbiotic germination tests were performed with mature seeds using BM-1 medium. In vitro seed germination and protocorm developmental stages were evaluated up to 20 weeks after sowing (Magrini et al. 2012).

The aim of this study is to determine asimbiotically germination, protocorm and plant growth rates in vitro conditions of seeds of Orchis pinetorum, Anacamptis pyramidalis, and Dactylorhiza nieschalkiorum species.

\section{MATERIAL AND MeTHODS}

In this study, mature seeds of Orchis mascula (L.) L. ssp. pinetorum (Boiss et Kotschy) Camus., Anacamptis pyramidalis (L.) L.C. Rich., and Dactylorhiza nieschalkiorum Bauman et Künkele. were used (Figure 1). The flowered plants were gathered in Bartın, Turkey (Figure 2).
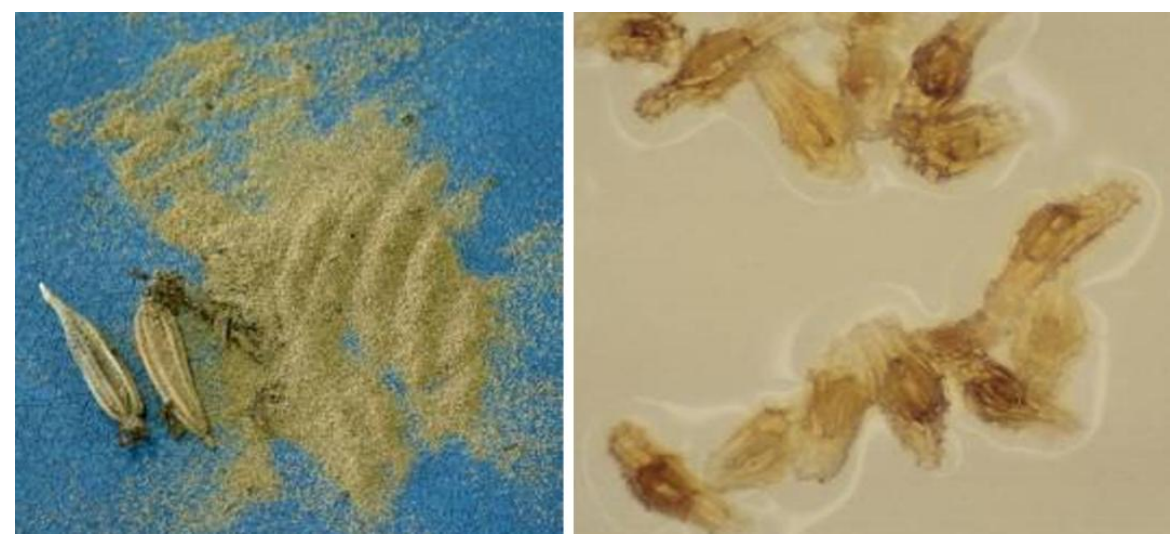

Figure 1. The capsules of orchid and the seeds (left), the images of orchid seeds under the stereomicroscope (right).
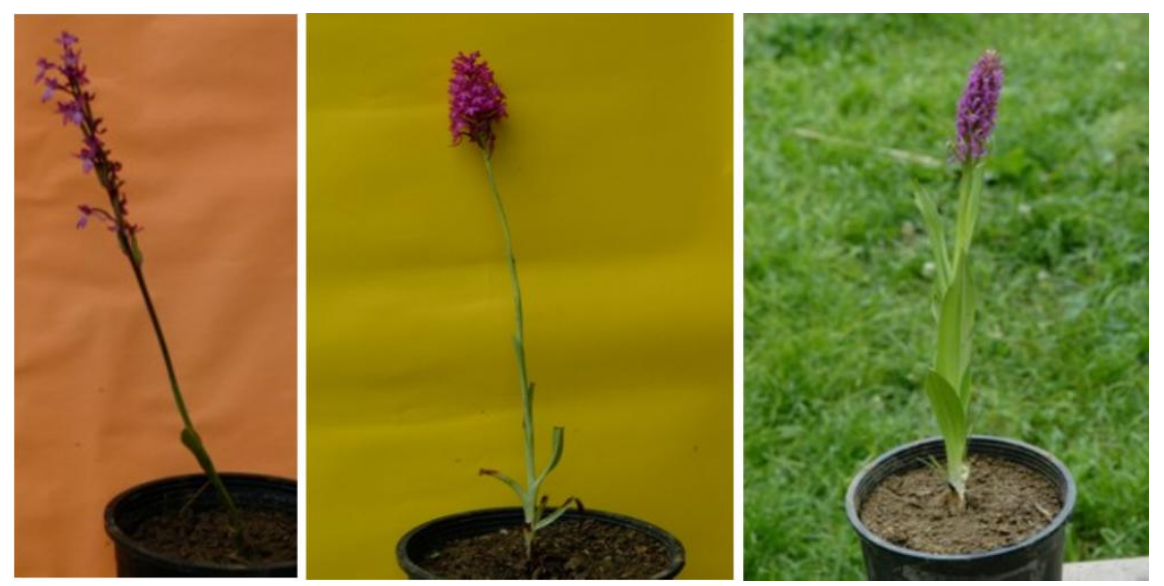

Figure 2. Flowered plants of Orchis mascula (L.) L. ssp. pinetorum (Boiss et Kotschy) Camus (left); Anacamptis pyramidalis (L.) L.C. Rich (medium); and Dactylorhiza nieschalkiorum Bauman et Künkele (right) 
During the study, 4 different basal media were used: $1 / 2$ MS (half-strength) (Murashige and Skog 1962), VW and DB (Van Waes and DeBergh 1986) and KC (Knudson 1946). As a carbon source, 15$30 \mathrm{~g} / \mathrm{L}(15 \mathrm{~g} / \mathrm{L}$ in $1 / 2 \mathrm{MS}, 30 \mathrm{~g} / \mathrm{L}$ in MS and $20 \mathrm{~g} / \mathrm{L}$ in other media) of sucrose (Difco-Bacto) was also added. In order to maintain the media at a semi-solidified state, $6 \mathrm{~g} / \mathrm{L}$ of agar (Difco-Bacto) was added and the $\mathrm{pH}$ levels were adjusted to 5.7-5.8.

Divided into petri dishes was $15-17 \mathrm{~mL}$ of nutrient media. The sterilization of nutrient media in autoclave was done under the following conditions: 1.2 atmospheric pressure and $121{ }^{\circ} \mathrm{C}$ heat for 20 $\min$. The glass and metal equipment used in the trials were sterilized at the same atmospheric pressure and heat for $120 \mathrm{~min}$. During the process of subculturing and growing the protocorms developed from germinated seeds, glass jars measuring $7 \times 10 \mathrm{~cm}$ were used. The jars were sterilized and filled with $70 \mathrm{~mL}$ of nutrient media ( $1 / 2 \mathrm{MS})$.

The orchid seeds were disinfected with $10 \%$ sodium hypochloride (household bleach) in which 2-3 drops of Tween-20 were added using small packets made of filter paper. The seeds were steeped in the treatment for $12 \mathrm{~min}$. sowing of the seeds for each treatment was done in repetitions according to $1 \mathrm{mg}$ of seed per repetition.

After completion of seed sowing in the petri dishes, they were incubated at $23 \pm 1{ }^{\circ} \mathrm{C}$ under constant darkness conditions until the protocorm formation period. The total number of seeds in each of the petri dishes was determined 3 months after sowing took place, using a stereo microscope. A month after this determination, only those protocorms that were in the form of a white sphere and that had reached the size of at least $2 \mathrm{~mm}$ were counted. The obtained protocorms were transferred into $1 / 2 \mathrm{MS}$ transfer medium and they were later exposed to $23 \pm 1{ }^{\circ} \mathrm{C}, 16 \mathrm{~h}$ /day luminous photoperiodicity and 3000 lux intensity light. After germination and protocorm formation occurred, all of the explants were transferred into $10 \mathrm{~cm}$ diameter petri dishes containing $1 / 2$ MS nutrient medium which was used as the transfer media. The protocorms were subcultured once in 4-5 weeks; however, no further changes were made in the nutrient medium or the dimensions of the petri dishes. The process of transfer into the fresh nutrient medium continued until the plant developmental stage and the transfer process was repeated once every 4-5 weeks after the plants started growing (Magrini et al. 2012).

The trials were set up in 10 repetitions and the findings underwent a variance analysis together with use of the STATISTICA 6.0 package program. The Duncan's t-test was used in lettering the various groups.

\section{Results}

Seeds of Orchis pinetorum, Anacamptis pyramidalis and Dactylorhiza nieschalkiorum were cultured in 4 different nutrient medias and germination, protocorm formation and plantlet growth rates were determined.

\section{a. Germination Rate}

Seeds of Orchis pinetorum, Anacamptis pyramidalis and Dactylorhiza nieschalkiorum were examined three months after cultivation (Figure 3) and germination rates were determined.

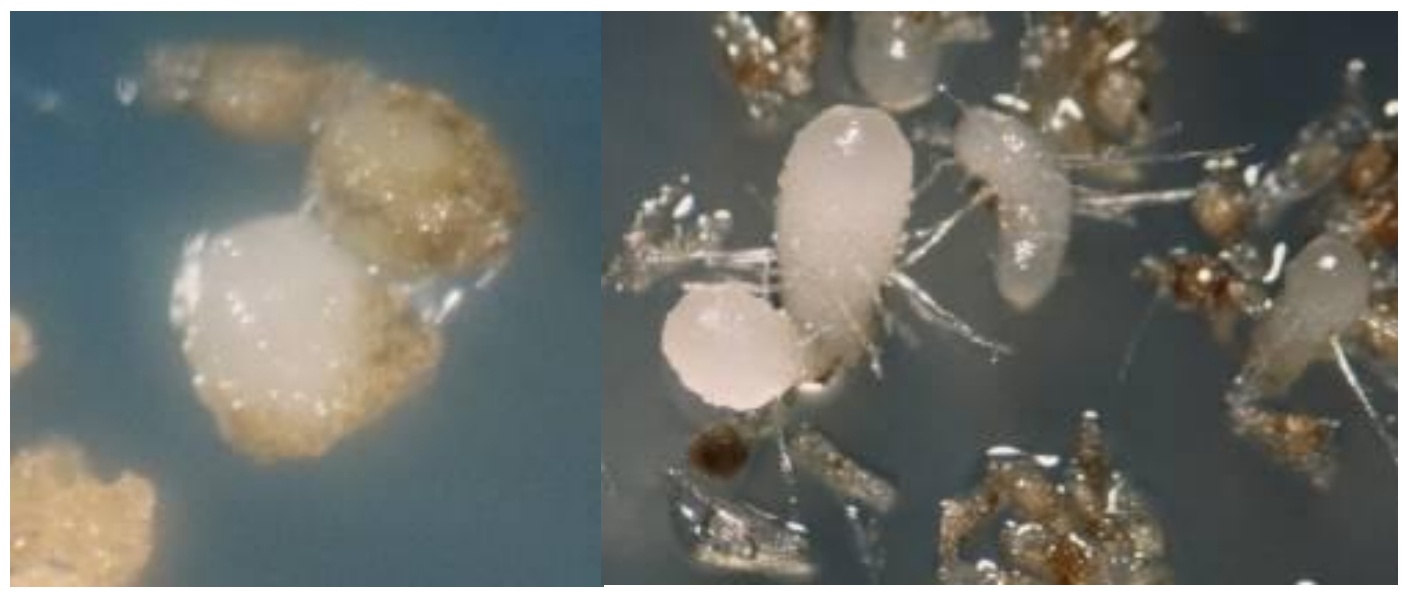

Figure 3. Germination of orchid seeds. 
Studies for Obtaining the Protocorms and Plantlets in Orchis pinetorum, Anacamptis pyramidalis, and Dactylorhiza nieschalkiorum under in vitro Conditions

The statistical analysis of the data obtained from the studies conducted to determine the effect of the species on the germination rate of the species which is one of the basic factors for the investigation reveals that $D$. nieschalkiorum from the tested terrestrial orchid species clearly distinguish positively from other species with a germination rate of $17.43 \%$. (6.95\%) and A. pyramidalis $(4.60 \%)$, respectively (Table 1 ).

Table 1. Germination rate of seeds of different terrestrial orchids species (\%)

\begin{tabular}{|c|c|}
\hline Terrestrial Orchid Species & Germination rate(\%) \\
\hline Orchis pinetorum & $6.95^{\mathrm{b}}$ \\
\hline Anacamptis pyramidalis & $4.60^{\mathrm{c}}$ \\
\hline Dactylorhiza nieschalkiorum & $17.43^{\mathrm{a}}$ \\
\hline
\end{tabular}

When the effect of the factors examined in the experiment (Species + Nutrient Medium) on the germination rate of interactions was investigated, the highest values which species effect reveals itself clearly were obtained from combinations which Dactylorhiza nieschalkiorum species exist. The highest germination rate was $24.41 \%$ with 'D. Nieschalkiorum + VW \& DB' and $20.34 \%$ with' $D$. nieschalkiorum $+\mathrm{KC}$ ' combinations (Table 2 ).

Table 2. Effects on germination rate (\%) of 'Species + Nutrient medium' interaction.

\begin{tabular}{|l|l|c|}
\hline Terrestrial Orchid Species & Nutrient medium & Germination rate(\%) \\
\hline \multirow{3}{*}{ Orchis pinetorum } & $1 / 2 \mathrm{MS}$ & $7.27^{\mathrm{cd}}$ \\
\cline { 2 - 3 } & $\mathrm{MS}$ & $9.58^{\mathrm{c}}$ \\
\cline { 2 - 3 } & $\mathrm{KC}$ & $6.46^{\mathrm{cd}}$ \\
\cline { 2 - 3 } & $\mathrm{VW} \& \mathrm{DB}$ & $4.50{ }^{\mathrm{d}-\mathrm{f}}$ \\
\hline \multirow{3}{*}{ Anacamptis pyramidalis } & $1 / 2 \mathrm{MS}$ & $4.19^{\mathrm{d}-\mathrm{f}}$ \\
\cline { 2 - 3 } & $\mathrm{MS}$ & $2.19^{\mathrm{f}}$ \\
\cline { 2 - 3 } & $\mathrm{KC}$ & $5.76^{\mathrm{c}}$ \\
\cline { 2 - 3 } & $\mathrm{VW \& DB}$ & $6.27^{\mathrm{cd}}$ \\
\hline \multirow{3}{*}{ Dactylorhiza nieschalkiorum } & $14.81^{\mathrm{b}}$ \\
\cline { 2 - 3 } & $\mathrm{MS}$ & $10.16^{\mathrm{c}}$ \\
\cline { 2 - 3 } & $\mathrm{KC}$ & $20.34^{\mathrm{ab}}$ \\
\cline { 2 - 3 } & $\mathrm{VW \& DB}$ & $24.41^{\mathrm{a}}$ \\
\hline
\end{tabular}

\section{b. Protocorm Rate}

As a result of the variance analyzes conducted to evaluate the differences in the rate of protocorm formation in species of $O$. pinetorum, A. pyramidalis and D. nieschalkiorum, it was identified that the difference between species and the combination of 'species + nutrient medium' was statistically significant at 5\% level and that the difference between the nutrient media was coincidentally originated.

D. nieschalkiorum, was found to be superior than the other two species in regard to this characteristics (\%13.10). There is no statistically significant differences between A. pyramidalis (\% 2.86) and $O$. pinetorum (\% 2.83) and they have low capacity in protocorm formation (Table 3, Figure 4).

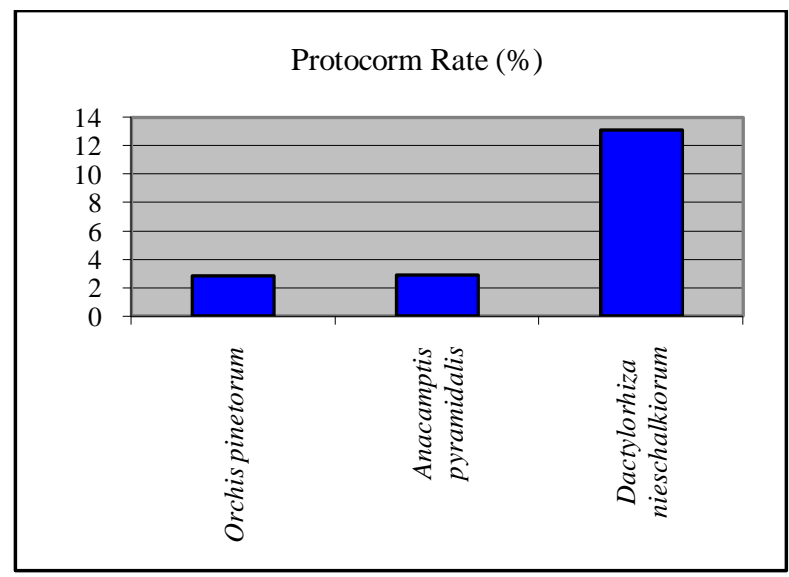

Figure 4. Effects on protocorm rate (\%) of different orchid species. 
Studies for Obtaining the Protocorms and Plantlets in Orchis pinetorum, Anacamptis pyramidalis, and Dactylorhiza nieschalkiorum under in vitro Conditions

Table 3. Effects on protocorm rate (\%) of different orchid species.

\begin{tabular}{|l|l|}
\hline Terrestrial Orchid Species & Protocorm rate (\%) \\
\hline O. pinetorum & $2.83^{\mathrm{b}}$ \\
\hline A. pyramidalis & $2.86^{\mathrm{b}}$ \\
\hline D. nieschalkiorum & $13.10^{\mathrm{a}}$ \\
\hline
\end{tabular}
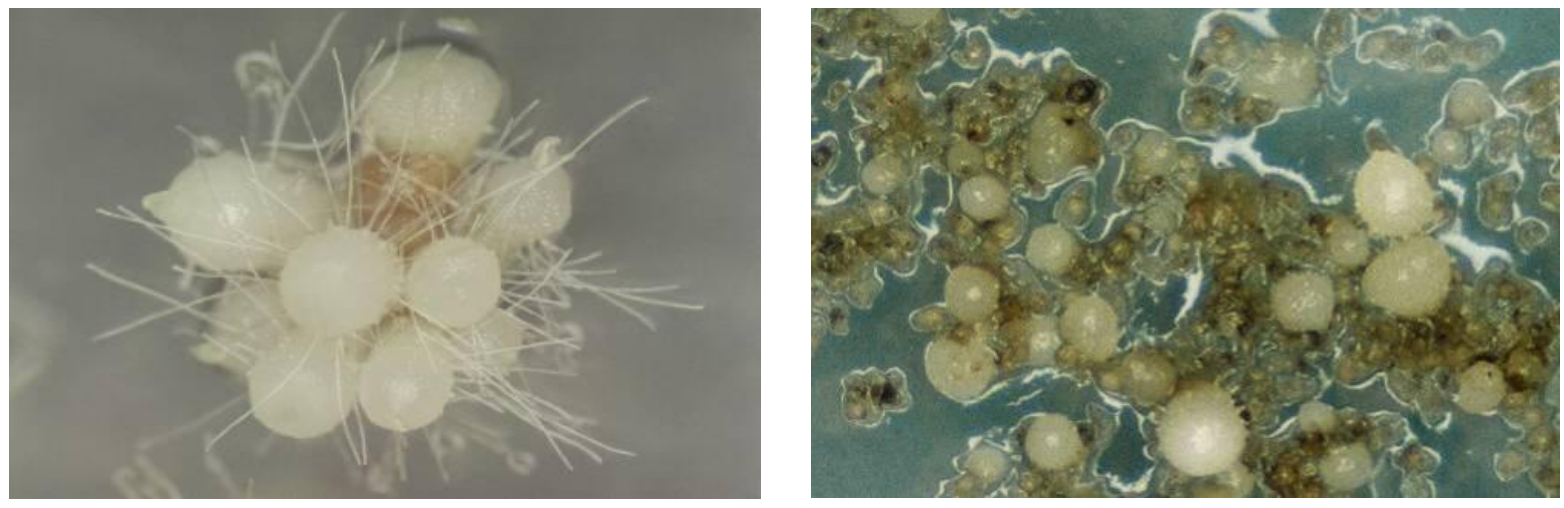

Figure 5. Protocorms of D. nieschalkiorum (left) and O. pinetorum (right)
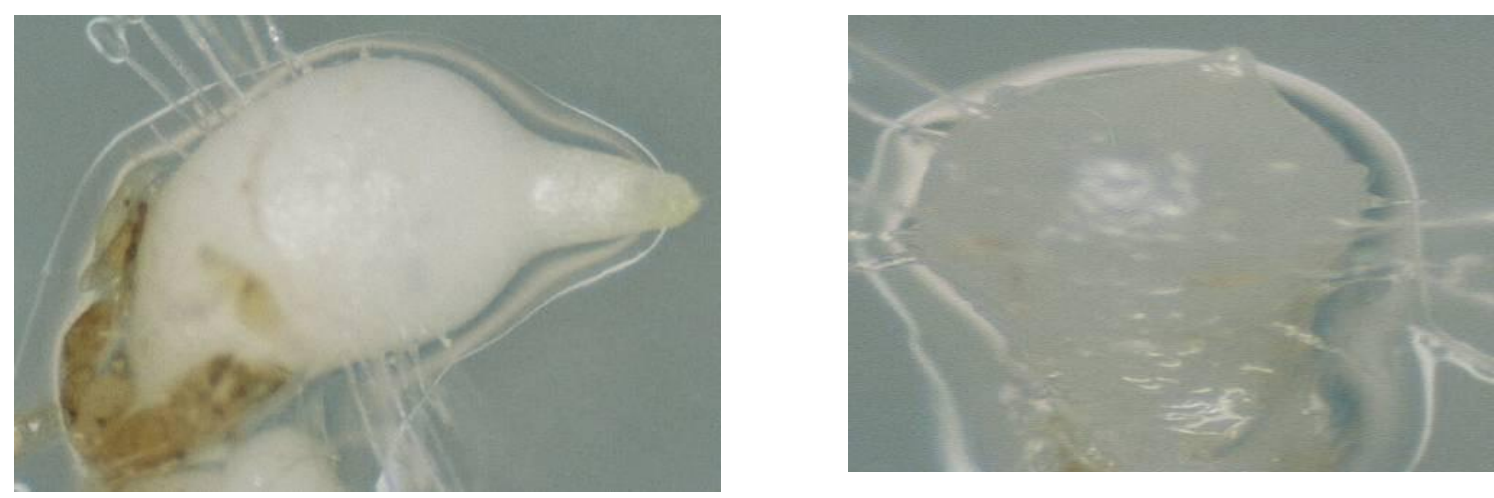

Figure 6. Protocorms of D. Nieschalkiorum (left) and A. pyramidalis (right)

The different nutrient media have no statistical effects on the species examined in terms of influencing the capacity of protocorm formation. None of the nutrient media(MS, $1 / 2 \mathrm{MS}$, KC ve VW\&DB) appeared to be particularly specific (Table 4 and Figure 7).

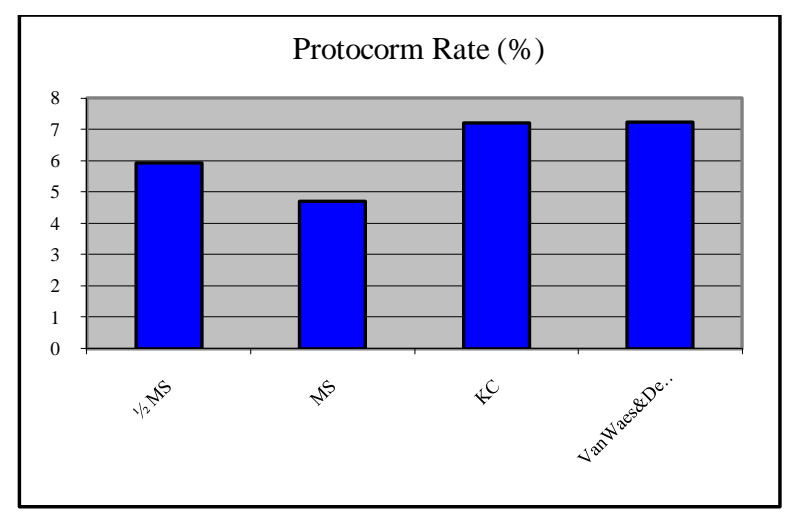

Figure 7. Effects on protocorm rate of different nutrient media (\%)

Table 4. Effects on protocorm rate of different nutrient media (\%)

\begin{tabular}{|l|c|}
\hline Nutrient medium & Protocorm rate $(\%)$ \\
\hline $1 / 2 \mathrm{MS}$ & $5.93^{\mathrm{a}}$ \\
\hline MS & $4.70^{\mathrm{a}}$ \\
\hline KC & $7.19^{\mathrm{a}}$ \\
\hline VW\&DB & $7.23^{\mathrm{a}}$ \\
\hline
\end{tabular}


Studies for Obtaining the Protocorms and Plantlets in Orchis pinetorum, Anacamptis pyramidalis, and Dactylorhiza nieschalkiorum under in vitro Conditions

In terms of the rate of protocorm formation, 'Species + Nutrient medium' interaction was identified to be important and the highest rate was found in 'D. nieschalkiorum + VW \& DB' combination with $19.21 \%$. This combination was followed by combinations of the same species with KC and $1 / 2 \mathrm{MS}$. In combination with $O$. pinetorum and A. pyramidalis species, this ratio is the lowest (Table 5, and Figure 8).

Table 5. Effects on protocorm rate of 'Species + Nutrient medium' interaction (\%)

\begin{tabular}{|l|l|l|}
\hline Species & Nutrient medium & Protocorm rate (\%) \\
\hline \multirow{5}{*}{ O. pinetorum } & $1 / 2 \mathrm{MS}$ & $3.47 \mathrm{~cd}$ \\
\cline { 2 - 3 } & $\mathrm{MS}$ & $4.36 \mathrm{~cd}$ \\
\cline { 2 - 3 } & $\mathrm{KC}$ & $3.47 \mathrm{~cd}$ \\
\cline { 2 - 3 } & $\mathrm{VW} \& \mathrm{DB}$ & $0.00 \mathrm{e}$ \\
\hline \multirow{5}{*}{ D. pyramidalis } & $1 / 2 \mathrm{MS}$ & $3.30 \mathrm{~cd}$ \\
\cline { 2 - 3 } & $\mathrm{MS}$ & $1.04 \mathrm{de}$ \\
\cline { 2 - 3 } & $\mathrm{KC}$ & $4.61 \mathrm{~cd}$ \\
\cline { 2 - 3 } & $\mathrm{VW} \& \mathrm{DB}$ & $2.47 \mathrm{~d}$ \\
\hline & $1 / 2 \mathrm{MS}$ & $11.02 \mathrm{ab}$ \\
\cline { 2 - 3 } & $\mathrm{MS}$ & $8.70 \mathrm{bc}$ \\
\cline { 2 - 3 } & $\mathrm{KC}$ & $13.49 \mathrm{ab}$ \\
\cline { 2 - 3 } & $\mathrm{VW} \& \mathrm{DB}$ & $19.21 \mathrm{a}$ \\
\hline
\end{tabular}

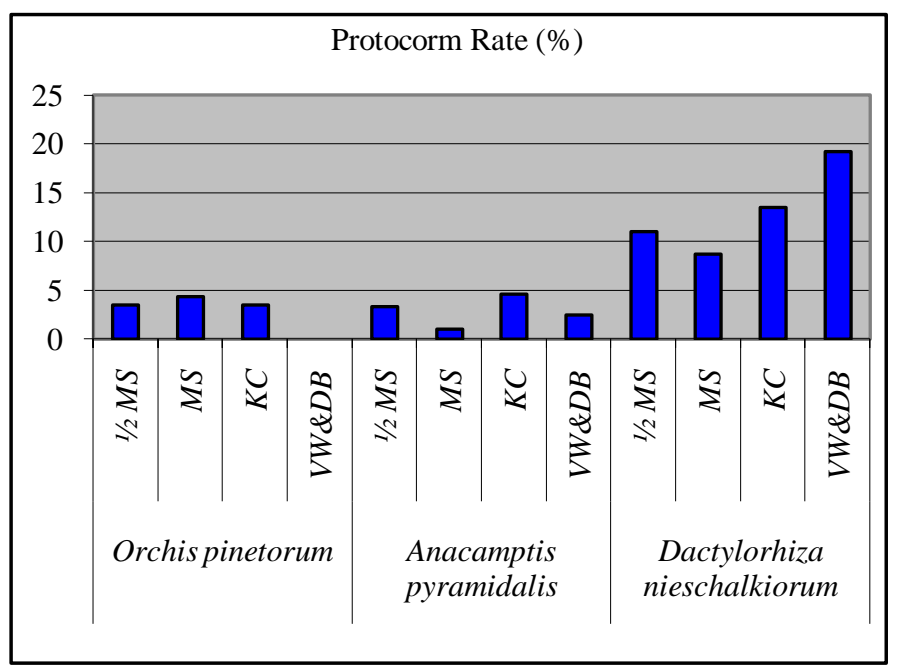

Figure 8. Effects on protocorm rate of 'Species + Nutrient medium' interaction (\%)

\section{c. Plantlet Rate}

Plantlets development was only achieved in the D. nieschalkiorum species (Figure 10). While the effect of different nutrient medias on plant growth rate was not statistically significant, the highest plant growth rate was obtained from VW \& DB nutrient medium with $8.11 \%$, followed by $1 / 2 \mathrm{MS}$ $(6.28 \%)$ and $\mathrm{KC}(6.25 \%)$ nutrient media, the lowest plantlet rate was determined in the MS medium with $3.79 \%$ (Table 6, and Figure 9).

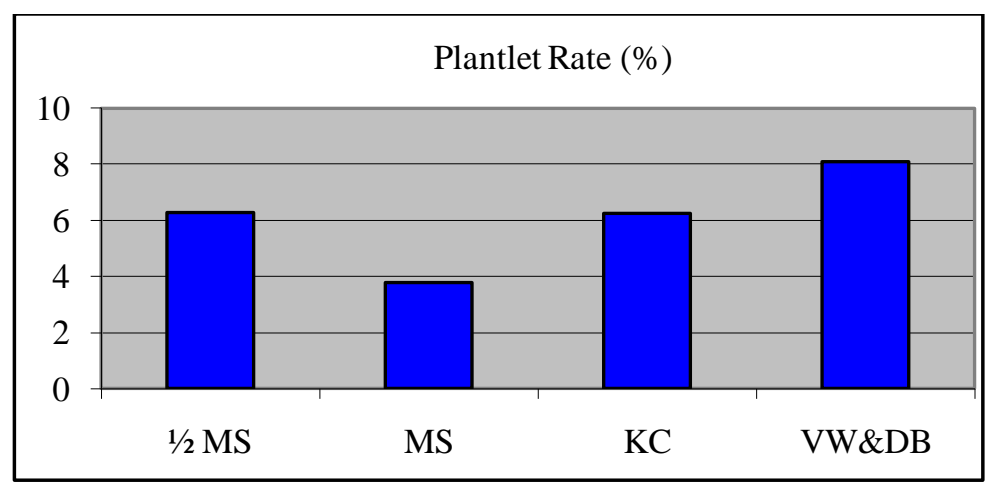

Figure9. Effects of different nutrient medias on plantlet rate in D. nieschalkiorum. 
Studies for Obtaining the Protocorms and Plantlets in Orchis pinetorum, Anacamptis pyramidalis, and Dactylorhiza nieschalkiorum under in vitro Conditions

Table6. Effects of different nutrient medias on plantlet rate in D. nieschalkiorum.

\begin{tabular}{|l|l|}
\hline Nutrient medium & Plantlet rate (\%) \\
\hline $1 / 2 \mathrm{MS}$ & $6.28^{\mathrm{a}}$ \\
\hline $\mathrm{MS}$ & $3.79^{\mathrm{a}}$ \\
\hline KC & $6.25^{\mathrm{a}}$ \\
\hline VW\&DB & $8.11^{\mathrm{a}}$ \\
\hline
\end{tabular}
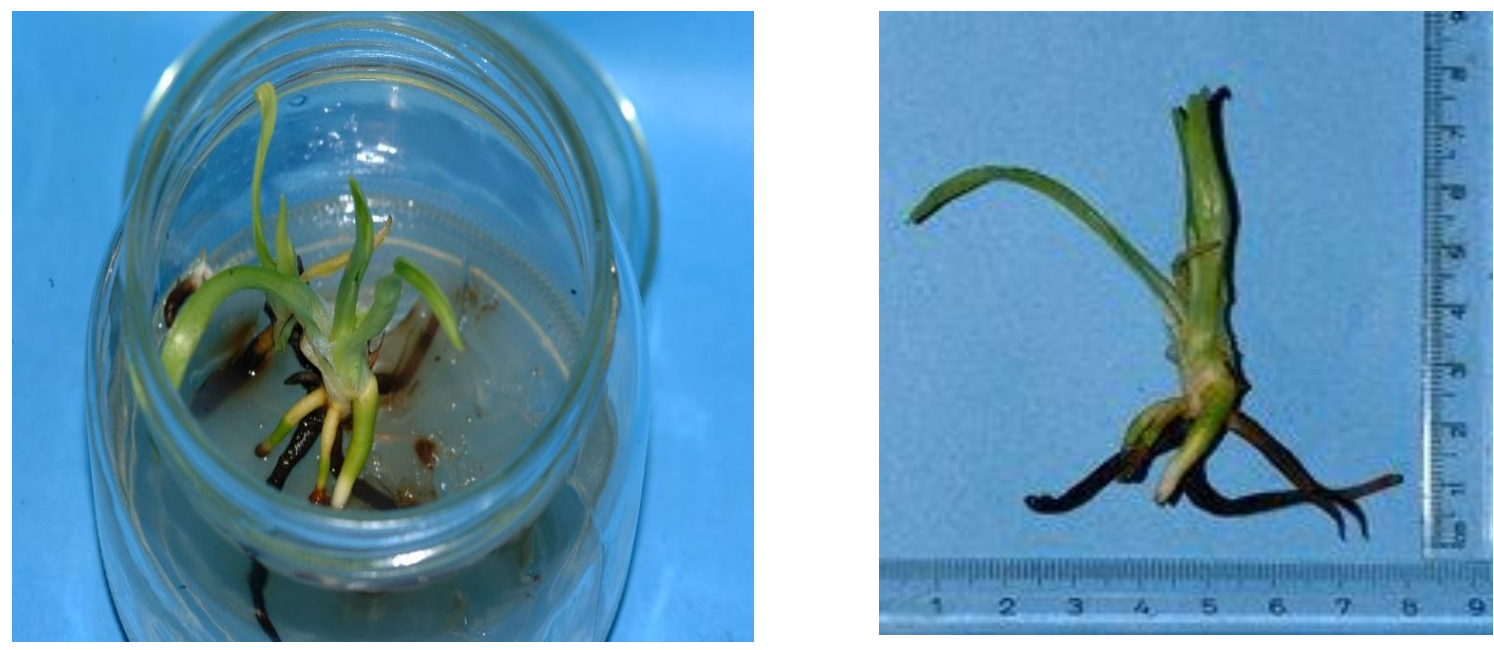

Figure 10. The plantlets of D. nieschalkiorum

\section{DISCUSSION}

Orchid seeds asymbiotic in vitro germination is supported by a large amount of information in the literature and among these, Van Waes and DeBergh and Knudson $\mathrm{C}$ were cited the most. Nutrient media composition is important for orchid seed germination as well as for tissue culture studies. Although epiphytic orchids needed intensive nutrient media, terrestrial orchids germinate better in diluted media. Hence, there has been an inclination to use diluted nutrient media compositions. Based on the literature, 3 main nutrient media, Murashige and Skoog medium, Knudson C medium and Van Waes and DeBergh medium, were used in our study.

In our research, the highest germination ratios $(24.41 \%-20.34 \%)$ were obtained in the Van Waes \& DeBergh and Knudson C medium. In fact, Önal (1999) reported that he obtained the highest germination ratio at $40 \%$ in Knudson C $+10 \%-20 \%$ banana extract in Serapias vomeracea. On the other hand, Özkoç and Dalci (1994) reported that they obtained the highest germination ratio at $25.1 \%$ in the Knudson C medium without inorganic nitrogen, in the study of Orchis laxiflora Lam. species in vitro seed germination. Kisakürek et al. (2009) also reported that they obtained the highest germination ratio in the KC medium in the study of Orchis coriophora, O.laxiflora, O.mascula and O.anatolica. The results of this research study and the literature support each other. The transfer of cultured seeds into the photoperiodic media after 3 months had a positive effect on growth. Protocorms turned green under light. The same observation was reported by Arditti (1967), Harley (1969) and Pierik et al.(1982). In the present study, the plantlets produced will be transferred to an ex vivo environment in 11 months and the highest plant growth ratio was obtained at $40.24 \%-57.65 \%$ with the KC medium. Önal (1999) reported that the plantlets were produced in 330 days, as was similar to our findings. He also added that the highest values were obtained in the KC medium with potato extract at different ratios on the basis of plant-producing culture percentage and the number of growing plants per mg. While protocorm formation occurs in all species tested, plantlets growth occurs only in D. nieschalkiorum species. Both the protocorm formation and the effect of nutrient media in plantlets growth were statistically insignificant.

\section{CONCLUSION}

In their habitat, less than $5 \%$ of orchid seeds can germinate. After germination, it takes duration as long as 2-16 years for the orchids to become mature. Furthermore, our study revealed that the 
Studies for Obtaining the Protocorms and Plantlets in Orchis pinetorum, Anacamptis pyramidalis, and Dactylorhiza nieschalkiorum under in vitro Conditions

production of $D$. nieschalkiorum plants (at approximately $10 \mathrm{~cm}$ tall) were able to be transferred to an ex vivo environment in 11 months.

The nutrient media composition had an effect on the orchid germination, protocorm and planlets ratio and it was observed that the half strenght nutrient media compositions were preferred. The Knudson C and Van Waes \& DeBergh medium was observed to be the most effective.

\section{REFERENCES}

[1] Anonymous., http://www.orchidsofbritainandeuropetest.uk/Orchis\%20pinetorum.html,15.04.2017. (2017).

[2] Arditti, J., Factors afecting of orchid seeds. Bot. Rev. 33, 1-97 (1967).

[3] Arditti, J., Aspects of the physiology of orchids. I: H.W. Woolhouse (Editor), Advances in Botanical Research,7. Academic Pres, New York, $422-697$ (1979).

[4] Davis, P.H., Flora of Turkey and East Aegan Islands. Vol.8. Edinburgh at the University Press. (1984).

[5] Gönülşen, N., Önal, K., Ercan, N., Yıldızgördü, K., Şekeroğlu, E., Biçici, M. and Eskalen, A., Investigations on the Propagation under in vitro and in vivo Conditions of Some Native Orchidaceae Species Growing in Aege and Mediterranean Regions. TÜBITTAK Project No: TBGAG-52 (in Turkish). (1996).

[6] Harley, J. L., The Biology of Mycorriza. Leonard Hill, London, UK, (Second edition): 1-334 (1969).

[7] Harvais, G., Growth requirements and development of Cypripedium reginae in axenic culture. Can. J. Bot.51:327-332 (1973).

[8] Kauth, P., Vendrame, W. and Kane, M. E., In vitro seed culture and seedling development of Calopogon tuberosus. Plant Cell Tissue Organ Cult. 85(1): 91-102 (2006).

[9] Kısakürek, Ş., Arpacı, B. B., Özdemir, A., Dalfesoğlu, K., Ergun, N. and Kaya, Y., Kahramanmaraş Doğal Florasında Yetişen ve Salep Üretiminde Kullanılan Bitkilerin Kültüre Alınabilme Olanakları. Research Reports, TAGEM Kahramanmaraş (in Turkish) (2009).

[10] Knudson, L., A new nutrient solution for germination of orchid seed. Amer. Orchid. Soc. Bull. 15: 214217 (1946).

[11] Magrini, S., Bronzo, F., Onofri, S. and Scoppola, A., Germinazione asimbiotica in vitro di semi immaturi di Orchis palustris Jacq. Studi Trent. Sci. Nat. 90: 159-164 (2012).

[12] Malmgren, S., Large-scale asymbiotic propagation of Cypripedium calceolus: Plant physiology from a surgeon's point of view. Botanic Gardens Micropropagation News 1: 59-63 (1992).

[13] Malmgren, S., Orchid propagation: theory and practice. In: Allen C (ed) North American native terrestrial orchids: propagation and production. North American Native Terrestrial Orchid Conference, Germantown, Maryland, USA, pp 63-71 (1996).

[14] Mead, J.W. and Bulard, C., Effects of vitamins and nitrogen sources on asymbiotic germination and development of Orchis laxiflora and Ophrys sphegodes. New Phytol. 74: 33-40 (1975).

[15] Murashige, T. and Skoog, F., A revised medium for rapid growth and bioassays with tobacco cultures. Physiol. Plant. 15: 473-497 (1962).

[16] Önal, K., In vitro propogation of some species from Orchidaceae family existing in the natural flora of Aegean Region. Turkish J. of Agriculture and Forestry 23(5):1057-1064(1999).

[17] Özkoç, I. and Dalc1, M., Germination of the seeds of Orchis laxiflora Lam. (Orchidaceae) through asymbiotic culture techniques. Turkish Journal of Botany 18: 461-464 (1994).

[18] Pierik, R.L.M., Steegmans, H.H.M., Elias, A. A., Stiekema, O.T.J. and Velde, van der, A. J., Effect of cytokinin and cultivar on shoot formation of Gerbera jamesonii. Neth. J. Agric.Sci. 30:341-346 (1982).

[19] Pierik, R.L.M., In vitro Culture of Higher Plants. Kluwer Acad. Publ., Dordrecht, The Netherlands, pp:149-158 (1987).

[20] Raghavan, V. and Torrey, J. G., Inorganic nitrogen nutrition of the seedling of the orchid Cattleya. Amer. J Bot. 51: 264-274(1964).

[21] Sezik, E., Orkidelerimiz (our Orchids). Sandoz Kültür Yayınları. No:6, 166 p. (in Turkish) (1984).

[22] Stewart, L.S. and Kane, M.E. Asymbiotic seed germination and in vitro seedling development of Habenaria macroceratitis (Orchidaceae), a rare Florida terrestrial orchid. Plant Cell Tissue and Organ Culture 86(2):147-158(2006). 
Studies for Obtaining the Protocorms and Plantlets in Orchis pinetorum, Anacamptis pyramidalis, and Dactylorhiza nieschalkiorum under in vitro Conditions

[23] Van Waes, J., Effect of activated charcoal on in vitro propagation of Western European orchids. Acta Hort.212(1):131-138 (1987).

[24] Van Waes, J.M., and DeBergh, P.C., In vitro germination of some western European Orchids. Physilogia Plantarum 67(2): 253-261 (1986).

Citation: C. GUMUS et al., "Studies for Obtaining the Protocorms and Plantlets in Orchis pinetorum, Anacamptis pyramidalis, and Dactylorhiza nieschalkiorum under in vitro Conditions", International Journal of Forestry and Horticulture (IJFH), vol. 3, no. 3, p. 28-36, 2017. http:// dx.doi.org/10.20431/2454-9487.030 3005

Copyright: (C) 2017 Authors. This is an open-access article distributed under the terms of the Creative Commons Attribution License, which permits unrestricted use, distribution, and reproduction in any medium, provided the original author and source are credited. 